\title{
ANÁLISE DA PERCEPÇÃO DE JOGADORES DE FUTEBOL AMADOR SOBRE MULHERES QUE PRATICAM O FUTEBOL
}

\author{
Frederico Jorge Saad Guirra \\ Universidade Federal de Mato Grosso, Barra do Garças, Mato Grosso, Brasil \\ Jacqueline Vieira Almeida \\ Universidade Federal de Mato Grosso, Barra do Garças, Mato Grosso, Brasil
}

\begin{abstract}
Resumo
O futebol feminino é uma modalidade esportiva marcada, desde a sua origem, pelo preconceito, desvalorizando as mulheres que o praticam. Sob essa ótica o presente estudo teve como principal objetivo analisar qual a percepção de jogadores de futebol amador da cidade de Aragarças - GO a respeito de mulheres que praticam o futebol. A metodologia utilizada foi uma pesquisa quali-quantitativa, baseada em um questionário aplicado e contando com material bibliográfico, por meio do qual os resultados desvelaram que, apesar da fala dos entrevistados, ainda existe um grande preconceito da sociedade contra mulheres que praticam tal esporte, como também a ausência de incentivos por parte da mídia e das entidades governamentais, fato que não acontece no futebol masculino.
\end{abstract}

Palavras-chave: Esporte. Futebol. Gênero. Sexualidade.

\section{Introdução}

Ao observarmos a história do esporte, notamos o quanto ela foi, por muito tempo, construída por e para personagens do gênero masculino, o que se deve ao fato de os papéis destinados a homens e mulheres terem sido designados pela sociedade. Silveira (2008, p. 26), nos relata que "Os papéis indicam padrões a serem seguidos, definindo o que é adequado ou não, aos homens e às mulheres. Eles ditam desde roupas, maneiras de se comportar, falar, dançar, jogar, enfim, o modo como homens e mulheres devem se relacionar". Nesse contexto, o papel da mulher permanece inferior ao do homem, pois, para Cruz et. al (2008, p.3):

\footnotetext{
Historicamente, as mulheres desempenharam papel secundário em relação aos homens em quaisquer setores da sociedade. Essa dita superioridade masculina foi construída culturalmente a partir das diferentes formas de educar homens e mulheres, o que conferiu competências e habilidades específicas para cada gênero. Escola e Família são consideradas as principais instituições responsáveis pela construção e/ou reprodução de valores estereotipados acerca das questões de gênero (CRUZ. et al, 2008, p.3).
}

Partindo dessa ideia, compreendemos por que as mulheres foram impedidas, durante muito tempo, de participarem de atividades esportivas, ficando o papel feminino limitado à maternidade, tendo sua imagem ligada a um ser extremamente sensível, delicado, tornando-se submissa ao homem, considerado socialmente um ser superior. Assim, a prática esportiva para elas se opunha a tais convicções. (GOELNNER, 2005). 
A prática esportiva feminina teve início, antes do século $\mathrm{XX}$, mas foi nas primeiras décadas desse mesmo século que elas conquistaram um espaço maior, possível graças à participação das mulheres nos Jogos Olímpicos Modernos. A primeira mulher brasileira a participar da competição foi a nadadora Maria Lenk, sendo este acontecimento, um grande marco para as mulheres, que viam sua inserção nos esportes ameaçada pela concepção culturalmente construída de que nasceram apenas para serem mães e esposas (GOELLNER, 2006). Mas a sociedade não via como certa a inserção da mulher em atividades consideradas masculinas; o ideal era que elas apenas fossem espectadoras (GOELLNER, 2005). Alimentava-se um medo nas famílias da época com o fato de que as mulheres estarem participando de competições esportivas pudesse levá-las à vulgarização.

Mesmo que as mulheres participassem de alguns eventos esportivos, o temor à desmoralização feminina frente à exibição e espetacularização do corpo se traduzia num fantasma a rondar as famílias, em especial, as da elite. A prática esportiva, o cuidado com a aparência, o desnudamento do corpo e o uso de artifícios estéticos, por exemplo, eram identificados como impulsionadores da modernização da mulher e da sua auto-afirmação na sociedade e, pelo seu contrário, como de natureza vulgar que a aproximava do universo da desonra e da prostituição (GOELLNER, 2005, p.145).

Segundo Franzini (2005), esse temor resultou na criação do Conselho Nacional de Desporto, que, no seu artigo 54, proibia as mulheres de praticar esportes que não eram condizentes com a sua feminilidade. "Em 1965, o Conselho Nacional de Desportos aprovou, a Deliberação $n^{\circ} 7$ que, em seu artigo segundo registrava não ser permitida a prática de lutas de qualquer natureza, futebol, futebol de salão, futebol de praia, pólo-aquático, rugby, halterofilismo e 'baseball'" (GOELLNER, 2005, p.145).

O movimento de inclusão da mulher no futebol aconteceu com a revogação dessa resolução, em 1979, que permitiu finalmente a prática de futebol feminino, e, a partir de 1981, várias equipes foram formadas, como Guarani, América e São Paulo (GOELNNER, 2005). Em 1987, havia 2 mil clubes e 40 mil jogadoras cadastradas na CBF - Confederação Brasileira de Futebol (DARIDO, 2002).

No final dos anos 80 e início dos anos 90, foi formada a Seleção Brasileira Feminina de Futebol, momento em que a imprensa começa a dar alguma notoriedade para esse esporte, mas sempre dando ênfase à sexualidade e feminilidade das jogadoras, tudo para manter presente a ideia de corpo já culturalmente definida (MORAES, 2012).

Começa uma mudança de pensamento, durante esse período; o esporte que antes era visto como prejudicial às funções biológicas da mulher passa a ser o motivo de sua erotização, ou seja, os meios mudaram, mas a essência desse pensamento prevaleceu. Citamos como exemplo o Campeonato Paulista Feminino de 2001, competição que visava atrair o público masculino, não pelas habilidades futebolísticas das jogadoras, mas, sim, pela beleza e sensualidade que elas deveriam demonstrar, e, para isso, jogavam maquiadas e com uniformes curtos (FRANZINI, 2005).

Mesmo diante desses preconceitos, a Seleção chegou a uma conquista histórica: a prata nos Jogos Olímpicos de Atenas, em 2004, surpreendendo o país e gerando um clamor da mídia pela valorização do esporte e das atletas. Com o fim da competição, os dirigentes, técnicos e comentaristas insistiram na estruturação do futebol feminino, mas o tempo passou e nada foi feito para que isso acontecesse (KNIJNIK, 2006). O futebol feminino, mesmo sem a 
prometida estruturação, seguiu se destacando e ganhou o ouro nos jogos Pan-Americanos em 2007, e o vice-campeonato mundial no mesmo ano. (SANTOS; MEDEIROS, 2011).

A principal competição de futebol feminino que temos, atualmente, é a Copa do Brasil, organizada pela CBF, formada por 32 equipes e cerca de 770 mulheres (PISANI, 2014). Referindo-se ao número de adeptas, Tiesler (2011, apud PISANI, 2014) relata que há mais de 30 milhões de jogadoras de futebol feminino registradas na Federação Internacional de Futebol e Associados (FIFA), e que, dos 168 países listados, apenas em 17 as atletas conseguem prover seu sustento como jogadoras de futebol.

Pensava-se que com a liberação do esporte feminino, ele assumiria um valor mais próximo do masculino, o que não pôde ser comprovado, na prática, porque, com o passar dos anos, os campeonatos foram surgindo e os times seguindo o mesmo ritmo, e, apesar do incentivo dado às atletas, seja com infraestrutura, patrocínio e divulgação, elas ainda se encontram à sombra do masculino. Como forma de melhor exemplificar a afirmação acima, podemos comparar uma atacante titular do CT - Centro de Treinamento do Oeste do Paraná -, que recebe o equivalente a $2 \%$ do salário de um atacante reserva do Atlético Paranaense (PISANI, 2014). Como o valor recebido é muito baixo, a maioria das jogadoras de futebol já sabe que não pode viver do futebol, e por isso muitas conciliam treinamento com estudos ou trabalho, visando garantir o futuro, ou, ao menos, preparar-se para ele.

Além disso, não podemos deixar de frisar o papel da mídia no processo de desenvolvimento do futebol feminino, pois, se analisarmos a sua forma de atuação, veremos que existe uma supervalorização do futebol masculino. A mesma mídia que transforma jogadores em "heróis" se esquece das mulheres, que, embora obtendo bons resultados, são ignoradas, e isso acaba gerando a problemática da falta de "heroínas" em quem as outras mulheres possam se espelhar (SOUZA; KNIJNIK, 2007).

Diante do apresentado, vimos emergir o objetivo deste estudo, qual seja, analisar qual a percepção de jogadores de futebol amador do gênero masculino, da cidade de Aragarças $\mathrm{GO}$, a respeito de mulheres que praticam o futebol.

\section{Procedimentos metodológicos}

O presente trabalho atende às "Diretrizes e Normas Regulamentares de Pesquisa Envolvendo Seres Humanos" da Resolução no 196/96 e 251/97, do Conselho Nacional de Saúde. Para a realização da coleta de dados foi entregue o Termo de Consentimento Livre e Esclarecido (TCLE) para cada participante, sendo que os menores de idade deveriam ser representados por pais ou responsáveis.

É uma pesquisa quali-quantitativa, na qual foram utilizadas duas fontes de pesquisa: a primeira de cunho bibliográfico, com um embasamento teórico de autores relacionados ao tema, para procurarmos entender, de forma mais específica, a problemática abordada e analisar os possíveis resultados; a segunda foi obtida por meio de um questionário fechado, constituído por oito perguntas ordenadas e as opções de respostas, que foi entregue pelo entrevistador e recolhido posteriormente (MARCONI; LAKATOS, 2002).

\section{Procedimentos para a coleta de dados}

O campo da pesquisa localiza-se na cidade de Aragarças - GO, cidade com um índice populacional pequeno, porém o número de grupos que se reúnem para jogar futebol é considerável. Além disso, eles se dividem em dois lugares, o estádio municipal chamado 
Raimundo Lopes de Abreu (Franciscão) e o campo de futebol socyte, conhecido popularmente como Aerobar. Os jogos que presenciamos aconteciam às terças, quartas e quintas, em diferentes horários.

Quanto aos procedimentos, foi realizado, primeiramente, um levantamento quanto ao número de associações existentes na cidade. Em seguida, optamos por um questionário fechado, devido à facilidade no seu preenchimento, tendo em vista que os entrevistados estavam no seu momento de lazer e, portanto, havia o receio de que perguntas abertas, que levassem mais tempo para serem respondidas, pudessem ser rejeitadas e não preenchidas, comprometendo, assim, o estudo.

Para a aplicação do questionário foi necessário, em um primeiro momento, explicarmos ao líder de cada associação o objetivo da pesquisa e a necessidade das respostas, e ele, por sua vez, reunia os participantes e repassava as informações. Para tanto, foi necessário estarmos nos campos de futebol em que se reuniam, com trinta minutos de antecedência. Os questionários eram entregues a cada um e a devolução aguardada no local.

Como a maioria dos jogadores chegava próximo ao começo dos treinos, muitos não se disponibilizaram a responder às perguntas, outros davam alguma desculpa, e, com isso, o número de questionários que poderia ser maior, acabou não superando as nossas expectativas.

\section{Apresentação dos dados e discussão dos resultados}

A amostra resultou em um grupo de 53 pessoas do gênero masculino, com idade entre 16 e 71 anos, integrantes de três associações de futebol amador da cidade de Aragarças- GO. A primeira chama-se "Associação dos amigos de Aragarças", existente há onze anos; a segunda chama-se "Associação do Indião" (antiga Associação do Zé Pezão), existente há vinte anos, e a terceira chama-se "Associação dos veteranos de Aragarças", existente há vinte e oito anos.

Das oito perguntas previamente selecionadas para o questionário, optamos por trabalhar com quatro, pois as respostas poderiam ser contempladas em outras questões, ao longo do texto. Em relação às perguntas selecionadas para nosso debate, os resultados encontram-se descritos abaixo.

Ao serem questionados se consideram o futebol feminino um esporte importante, 52 entrevistados $(98,11 \%)$ responderam que sim e 1 entrevistado $(1,89 \%)$ respondeu que não. Esse pensamento pode estar relacionado às grandes conquistas do futebol feminino brasileiro, como a prata nos jogos olímpicos de Atenas (2004), o ouro nos jogos Pan-Americanos (2007) e o vice-campeonato mundial nesse mesmo ano. Aliando-se a esses resultados temos um grande destaque individual, que é a jogadora Marta, eleita melhor jogadora do mundo pela FIFA, nos anos de 2006 a 2009 (SANTOS; MEDEIROS, 2011).

Assim como todas as outras modalidades esportivas, o futebol feminino é importante, não só pelas grandes conquistas, mas também pelo grande número de praticantes. Mas, ao analisar a atuação da Confederação Brasileira de Futebol (CBF), em relação ao futebol feminino, o que vemos é que ela não corrobora a mesma opinião do nosso grupo entrevistado. Dessa forma, esperava-se que a maior entidade do futebol brasileiro, responsável por inúmeros campeonatos masculinos, não se limitasse apenas a um torneio feminino durante o ano inteiro, que é a Copa do Brasil (CBF, 2014).

Se no Brasil os responsáveis pelo futebol nacional não dão ao futebol feminino a importância a ele devida, nos Estados Unidos nossas atletas são muito prestigiadas, como pode ser percebido no relato abaixo sobre a liga americana: 
No início da primeira liga, em 2009, era permitido a cada time norte americano assinar contrato com até cinco jogadoras estrangeiras, a escolha das atletas foi realizada pelo sistema draft, que significa recrutamento. $\mathrm{O}$ draft existe para garantir o equilíbrio da competição e através dele cada equipe de futebol de mulheres teve direito a escolher uma atleta estrangeira, por rodada, para compor o grupo. É interessante notar que quatro das cinco primeiras jogadoras estrangeiras escaladas para atuarem na Liga, no ano de 2009, eram brasileiras. Já no primeiro ano de competição da Women's Professional Soccer, dez jogadoras brasileiras estavam inscritas na Liga, contra quatro japonesas, três australianas, três canadenses, duas francesas, duas inglesas, duas suecas, uma chinesa e uma islandesa. Mesmo que no Brasil a mulher jogadora de futebol seja uma "mercadoria sem valor", no exterior as brasileiras são lembradas e contratas quase sempre como primeira opção (PISANI, 2014, p. 6).

Ao serem questionados se acreditam que é preciso ter mais incentivo da mídia, sociedade e entidades governamentais para o futebol feminino, 51 entrevistados $(96,23 \%)$ responderam que sim e 2 entrevistados $(3,77 \%)$ responderam que não. Quanto à falta de incentivo, esse é um tema muito discutido por diversos autores em seus artigos, principalmente o que versa sobre a fraca estrutura do futebol feminino no Brasil, incluindo, nesse bojo, a falta de apoio, além do papel sem foco, que a mídia confere, às poucas divulgações da modalidade:

[...] é precária a estruturação da modalidade no país, pois são escassos os campeonatos, as contratações das atletas são efêmeras e, praticamente, inexistem políticas privadas e públicas direcionadas para o incentivo às meninas e mulheres que desejam praticar esse esporte, seja como participantes eventuais, seja como atletas de alto rendimento. Para além destas situações a mídia esportiva pouco espaço confere ao futebol feminino e quando o faz, geralmente, menciona não tanto os talentos esportivos das atletas, árbitras ou treinadoras mas a sua imagem e o seu comportamento (GOELLNER, 2005, p.149).

Quando se trata do papel da mídia no futebol, torna-se inevitável não compararmos o masculino com o feminino, pois, enquanto o primeiro é transmitido quase que diariamente, em grandes emissoras de televisão, com rodas de debates, jogos de diversos campeonatos, o segundo se limita a ter jogos transmitidos em emissoras bem menores, conforme o relato abaixo:

Os meios de comunicação o veiculam muito pouco, enquanto que os homens aparecem quase todos os dias nos jornais, revistas e telejornais; seus jogos são televisionados periodicamente, são até dois jogos dos campeonatos nacionais, estaduais e até internacionais durante a semana na TV aberta, se falarmos das TVs por assinatura há inclusive a possibilidade de se comprar todos os jogos de um determinado campeonato. Enquanto que os jogos do campeonato Paulista de futebol feminino, Copa do Brasil feminina, por exemplo, ficam relegados aos horários de pouco ibope e às vezes televisionados por emissoras de menor expressão, pois as grandes não demonstram muito interesse em transmiti-los (SARDINHA, 2011, p. 97). 
A falta de incentivo da mídia, da sociedade e das entidades governamentais gera um dos maiores problemas do esporte, a instabilidade dos clubes, que, sem investimento e patrocínio não conseguem arcar com as despesas das atletas e acabam fechando as portas, fato que aconteceu com o Santos Futebol Clube, no ano de 2012 (PISANI, 2014).

Quando questionados se acreditam que ainda existe muito preconceito da sociedade contra meninas que jogam futebol, 44 entrevistados $(83,02 \%)$ responderam que sim, e 9 entrevistados $(16,98 \%)$ responderam que não. Preconceito é, sim, algo ainda muito presente no futebol feminino, e, não por acaso, houve tantos empecilhos na liberação da prática da modalidade para as mulheres. Segundo Magalhães (2008, p. 28), "Os preconceitos foram historicamente construídos pela e na nossa cultura, sendo alguns dos elementos que fazem com que o questionamento sobre a participação da mulher no futebol sempre reapareça". Esse preconceito está associado a estereótipos sociais que sempre estiveram presentes, pois

[...] o preconceito está vinculado à necessidade de assegurar a reprodução do arquétipo feminino de "maternidade" e "dona do lar" de maneira a impedir, bloquear ou retardar a quebra da hegemonia econômica capitalista que reconhece a divisão binária entre "homem/sexo forte" e "mulher/sexo frágil" como a única legítima aos olhos da sociedade (TEIXEIRA; CARMINHA, 2013, p. 267):

Há também o receio da masculinização que o futebol poderia produzir nas praticantes, uma vez que "[...]direciona-se, não apenas para as modificações de seu caráter, mas, sobretudo, para a sua aparência. Afinal, julgava-se/ julga-se o quão feminina é uma mulher pela exterioridade do seu corpo." (GOELLNER, 2005, p.148).

A mesma autora ainda nos afirma que:

Os argumentos que sustentam esses discursos estão ancorados em uma representação essencialista dos gêneros, segundo a qual, a cada sexo correspondem algumas características que lhe são inerentes e, estas os define. Pressupõe, portanto, a existência de uma certa essência masculina e/ou feminina considerada natural e imutável (2005b, p. 148).

Nesse contexto, pode-se perceber que

[...] as formas de preconceito mais evidentes no contexto do futebol feminino são a segregação, a exclusão, o cerceamento da mulher em determinadas práticas esportivas consideradas femininas, limitação na escolha das práticas esportivas, erotização do corpo feminino e vigilância sobre a identidade de gênero das atletas (TEIXEIRA; CARMINHA, 2013, p. 282).

Essa erotização do corpo feminino ficou evidente, quando a principal Federação esportiva do País, a Federação Paulista de Futebol (FPF), estipulou condições para que as jogadoras pudessem participar do Campeonato Paulista de Futebol, em 2001, dentre as quais, ter cabelos compridos e idade não superior a 23 anos (KNIJNIK; VASCONCELLOS, 2003). Diante dessa imposição, as meninas que tivessem cabelos raspados eram discriminadas e não 
tinham permissão para participar, o objetivo era de realizar "[...] um campeonato bom e bonito, que unisse o "futebol à feminilidade"' (KNIJNIK; VASCONCELLOS, 2003, p.4).

Goellner (2005, p.149) ressalta que algumas mulheres, por amor ao esporte acabam cedendo às exigências que lhes são impostas e "[...] moldam-se aos padrões masculinos de modo a não questionar nem os preconceitos, nem as regras que o regem, expresso em atitudes, piadas, comportamentos, posturas corporais e discursos".

Quando os atletas amadores foram questionados sobre se a mulher que joga futebol pode ter sua orientação sexual influenciada pela modalidade, 10 entrevistados $(18,87 \%)$ responderam que sim e 43 entrevistados $(81,13 \%)$ responderam que não. Esse tema está relacionado à questão de preconceito discutida anteriormente, mas debater o assunto em uma pergunta específica se faz necessário, por entendermos que esta pode ser a principal e mais severa forma de preconceito contra o futebol feminino. Mesmo não convergindo com os resultados desta pesquisa, "[...] a homossexualidade encontra-se bastante presente na percepção das pessoas em relação ao futebol feminino" (D'ÁVILA, SOUZA JÚNIOR, 2009, p.38).

Em uma entrevista realizada pelo Jornal Folha de S. Paulo, com a ex-jogadora da Seleção Brasileira de Futebol Feminino, a meia atacante Sissi, no ano de 2010, quando questionada sobre os preconceitos que enfrentou durante sua carreira, destacou que:

O preconceito que mais enfrentei foi por ser jogadora de futebol. Falavam que futebol não era para mulher, que quem jogava futebol era sapatão. Nunca deixei que isso mudasse o que eu queria fazer. Sofri mais preconceito por ser uma mulher que optou por jogar futebol do que por racismo. Até mesmo dentro da própria família.

Percebe-se que a visão homossexual atribuída às atletas dá-se em todos os lugares, inclusive por pessoas da própria família. Para Goellner (2005) o fato de o futebol ser um esporte masculino, aos olhos da sociedade, as mulheres que o praticam convivem com a dúvida das pessoas sobre sua sexualidade. Ela ainda afirma que:

Agrega-se [...] ao discurso da masculinização da mulher a associação entre a aparência corporal e a identidade sexual, ou melhor, a suspeição de que a mulher que habita esse corpo "viril " vivencia seus desejos, seus amores e seus prazeres a partir de um referente que não aquele considerado como "normal", qual seja o da heterossexualidade (GOELLNER, 2005, p.149).

Nesse contexto, masculinização e homossexualidade, estão interligadas e definidas pela sociedade como consequência às atletas que praticam essa modalidade esportiva, o que constitui uma inverdade, pois o futebol não pode ser visto como um agente que influencia diretamente nesse tipo de escolha, que é pessoal e individual. Para Baptista e Otesbelgue (2013, p.84) "[...] tanto hetereoafetivas como homoafetivas podem gostar e praticar este esporte", o que deixa claro que o estereótipo atribuído a mulheres que gostam do futebol, na verdade, se dá muito mais como um preconceito da sociedade, mostrando que ele ainda existe, e ainda é muito presente entre as pessoas.

Magalhães (2008) questiona a relação entre homoafetividade e futebol, esclarecendo que muitas homossexuais nunca tiveram contato com o esporte e que sexualidade nada mais é do que uma questão de escolha individual. 
[...] ser homossexual é uma consequência não da prática do esporte, mas da própria condição da mulher que se assume homossexual e coincidentemente gosta de futsal, portanto, não se pode generalizar. Se o futsal/futebol é masculizante, ele não pode ser considerado o "culpado" pela orientação sexual das jogadoras lésbicas (OLIVEIRA, 2008, p. 41).

É fato que as mulheres, quando se inserem em modalidades esportivas dominadas pelos homens sempre se deparam com esse tipo de preconceito, porque "[...] as suas práticas estão envoltas no estigma da homossexualidade - e uma vez que o rótulo, o estereótipo está grudado na pessoa ou naquele campo social (no caso, o futebol feminino), ele dificilmente será retirado" (KNIJNIK, 2006, p. 393). Essa constatação pode ainda ser percebida, de forma muito enfática, no meio social, o que demonstra que as ideias propagadas no início do século $\mathrm{XX}$, que viam nas práticas esportivas como espaços tipicamente masculinos, ainda se encontram arraigadas em nosso meio, gerando barreiras e muita exclusão.

\title{
Considerações finais
}

A análise dos resultados deste estudo nos permitiu compreender que os jogadores de futebol amador da cidade de Aragarças - GO reconhecem a importância do futebol feminino, como também concordam que há falta de incentivo da mídia e das entidades governamentais para o pleno desenvolvimento dessa modalidade esportiva para mulheres. Para a maioria dos entrevistados, ainda existe muito preconceito contra meninas que jogam futebol, porém eles não acreditam que essa prática possa influenciar na orientação sexual das praticantes. Os resultados encontrados foram considerados satisfatórios para os objetivos traçados neste estudo, embora saibamos não condizerem com a realidade encontrada nos diversos lugares, onde a presença feminina ainda é vista sob a lente do preconceito e da exclusão.

Espera-se que as questões discutidas neste texto, tais como homossexualidade, masculinização e futebol possam motivar pesquisas que levantem novas possibilidades de temáticas, como, por exemplo, a homofobia tão presente no esporte.

Nesse cenário, somos sabedores de que as mulheres lutaram e ainda lutam pela conquista de condições de igualdade de direitos na sociedade, reconhecendo que muito já foi conquistado, mas ainda hão de percorrer um longo caminho para vencerem as barreiras que sempre lhes foram impostas, seja no esporte, como na política, no campo profissional, dentre tantos outros que podem ser citados. Quando se trata de uma área considerada masculina, como o futebol, a problemática é ainda maior; o preconceito e a discriminação vão desde a "suposta" falta de capacidade ou habilidade até a influência na orientação sexual que esse esporte poderia gerar em mulheres que o praticam.

\section{ANALYSIS OF FOOTBALL PLAYERS OF PERCEPTION ON AMATEUR WOMEN PRACTICING THE FOOTBALL}

\begin{abstract}
Women's football is a sport marked from the outset by prejudice, devaluing women who practice it. Under this view the present study aimed to analyze the perception of amateur footballers City Aragarças - GO about women who play football. The methodology used was a qualitative and quantitative research, bibliographic and documentary evidence, by means of which the results unveiled that despite the talk of respondents, there is still a lot of prejudice
\end{abstract}


in society against women playing football, but also the lack of incentives for the media, and government entities, which did not happen in men's soccer.

Keywords: Sport. Football. Gender. Sexuality.

\title{
ANÁLISIS DE LOS FUTBOLISTAS DE PERCEPCIÓN SOBRE LA MUJER DE AFICIONADOS QUE PRACTICAN EI FÚTBOL
}

\begin{abstract}
Resumen
El fútbol femenino es un deporte marcado desde el principio por el prejuicio, la devaluación de las mujeres que lo practican. Bajo este punto de vista el presente estudio tuvo como objetivo analizar la percepción de los futbolistas amateurs Ciudad Aragarcas - GO acerca de las mujeres que juegan al fútbol. La metodología utilizada fue una evidencia cualitativa y la investigación cuantitativa, bibliográfico y documental, mediante el cual los resultados revelaron que a pesar de la charla de los encuestados, todavía hay muchos prejuicios en la sociedad contra las mujeres jugando al fútbol, sino también la falta de incentivos para los medios de comunicación y entidades de gobierno, lo que no ocurrió en el fútbol masculino.
\end{abstract}

Palabras clave: Deporte. Fútbol. Género. Sexualidad.

\section{Referências}

BAPTISTA, T. J. R.; OTESBELGUE, R. C. Menina tem que se transformar em menino para jogar futebol? Revista Kinesis, v. 31, n. 1, 2013.

BASTOS, M. "Sofri mais por ser mulher do que pela cor da pele". São Paulo, mai. 2010. Disponível em

<http://www1.folha.uol.com.br/fsp/especial/fj3005201007.htm> Acesso em 15 dez. 2014.

CONFEDERAÇÃO BRASILEIRA DE FUTEBOL. Disponível em < http://www.cbf.com.br/competicoes/brasileiro-serie-a\#.VL2vkdLF_E > Acesso em 15 dez. 2014.

CRUZ, M. M. S. et al. O futebol feminino em Guanambi: realidade vestida de preconceito. Unimontes Científica, v. 10, n. 1/2, p. pág. 2-11, 2011.

D’ÁVILA, L. B.; DE SOUZA JÚNIOR, O. M. Futebol feminino e sexualidade. Revista das Faculdades Integradas Claretianas, n. 2, p. 31, jan/dez, 2009.

DARIDO, S. C. Futebol feminino no Brasil: do seu início à prática pedagógica. Motriz, v. 8, n. 2, p. 43-49, 2002.

FRANZINI, F. Futebol é “coisa para macho?": Pequeno esboço para uma história das mulheres no país do futebol. Revista Brasileira de História, v. 25, n. 50, p. 315-328, 2005.

GOELLNER, S. V. Mulheres e futebol no Brasil: entre sombras e visibilidades. Revista Brasileira de Educação Física e Esporte, São Paulo, v.19, n.2, p.143-51, abr./jun. 2005. 
KNIJNIK, J. D.; VASCONCELLOS, E. G. Mulheres na área no país do futebol perigo de gol. Mulher e Esporte: mitos e verdades. Barueri: Manole, p. 165-175, 2003.

KNIJNIK, J. D. Femininos e Masculinos no Futebol Brasileiro. 2006, 475p. Tese (Doutorado em Psicologia) - Instituto de psicologia da Universidade de São Paulo, USP, São Paulo, 2006.

MARCONI, M. A; LAKATOS, E. M. Técnicas de pesquisa. 5. ed. São Paulo: Atlas S. A. 2002.

MAGALHÃES, S. L. F. Memória, futebol e mulher: anonimato, oficialização e seus reflexos na capital paraense (1980-2007). Recorde: Revista de História do Esporte, v. 1, n. 2, 2008.

MORAES, E.V. As mulheres também são boas de bola: histórias de vida de jogadoras baianas (1970 - 1990).2012, 287p. Tese (Doutorado em História) - Faculdade de História, PUCSP, São Paulo, 2012.

OLIVEIRA, C. S. Mulheres em quadra: o futsal feminino fora do armário. 2008. 56f. Trabalho de Conclusão de Curso (Graduação em Educação Física) Universidade Federal de Mato Grosso do Sul, Campo Grande, 2008.

PISANI, M. da S. Migrações e deslocamentos de jogadoras de futebol: mercadoria que ninguém compra? Revista Esporte e Sociedade, ano 9, n. 23, p. 1-10, março/2014.

SANTOS, D. S.; MEDEIROS, A.G.A. O futebol feminino no discurso televisivo. Revista Brasileira de Ciências do Esporte, v. 34, n. 1, p. 185-196, 2011.

SARDINHA, E. M. A estrutura do futebol feminino no Brasil. Revista Hórus, v.5, n. 1, p. 93$112 \mathrm{Jan} / \mathrm{Mar}, 2011$

SILVEIRA, R. da. Esporte, homossexualidade e amizade: estudo etnográfico sobre o associativismo do futsal feminino. 156 f. 2008. Dissertação (Mestrado em Ciências do Movimento Humano) -Programa de Pós-Graduação em Ciências do Movimento Humano, Universidade Federal do Rio Grande do Sul, Porto Alegre, 2008.

SOUZA, J. S. S.; KNIJNIK, J. D. A mulher invisível: gênero e esporte em um dos maiores jornais diários do Brasil. Revista Brasileira de Educação Física e Esporte, v. 21, n. 1, p. 3548, 2007.

TEIXEIRA, F. L. S; DE OLIVEIRA C. I. Preconceito no futebol feminino brasileiro: uma revisão sistemática. Movimento (ESEF/UFRGS), v. 19, n. 1, p. 265-287, 2013.

Recebido em: 19/02/2015

Revisado em: 13/07/2015

Aprovado em: 01/09/2015 
Endereço para correspondência:

Frederico Jorge Saad guirra

fredguirra@uol.com.br

Universidade Federal do Mato Grosso

Avenida Valdon Varjão, nº 6.390.

Barra do Garças - Mato Grosso.

CEP: 78600-000 